\title{
Correction to: Differential effects of chronic and acute simulated seawater intrusion on tidal freshwater marsh carbon cycling
}

\author{
Ellen R. Herbert $\mathbb{D} \cdot$ Joseph Schubauer-Berigan - Christopher B. Craft
}

Published online: 28 October 2019

(C) Springer Nature Switzerland AG 2019

Correction to Biogeochemistry (2018) 138:137-154

https://doi.org/10.1007/s10533-018-0436-z

In the original publication, in the Methods section at the end of the section Gas Exchange Measurements, the following information was missing: "For methane, we dropped one to two data points, as appropriate, to improve the $r$ squared of the regression of methane concentration versus time to $\geq 0.85$. These changes did not affect the findings of the paper."

The original article can be found online at https:// doi.org/10.1007/s10533-018-0436-z.

E. R. Herbert · C. B. Craft ( $\square)$

School of Public and Environmental Affairs, Indiana

University, Bloomington, IN 47405, USA

e-mail: ccraft@indiana.edu

E. R. Herbert

e-mail: eherbert@ducks.org

J. Schubauer-Berigan

US Environmental Protection Agency, Office of Research and Development, National Risk Management Research

Laboratory, Cincinnati, OH 45268, USA 